\title{
Blasting Vibration Safety Criterion Analysis with Equivalent Elastic Boundary: Based on Accurate Loading Model
}

\author{
Qingwen Li, ${ }^{1}$ Lan Qiao, ${ }^{1}$ Gautam Dasgupta, ${ }^{2}$ Siwei Ma, ${ }^{2}$ Liping Wang, ${ }^{3}$ and Jianghui Dong ${ }^{4}$ \\ ${ }^{1}$ The School of Civil and Environmental Engineering, University of Science and Technology Beijing, Beijing 100083, China \\ ${ }^{2}$ Department of Civil Engineering and Engineering Mechanics, Columbia University, New York, NY 10027, USA \\ ${ }^{3}$ School of Computer Science, Engineering and Mathematics, Flinders University, Adelaide, SA 5042, Australia \\ ${ }^{4}$ School of Natural and Built Environments, University of South Australia, Adelaide, SA 5095, Australia
}

Correspondence should be addressed to Qingwen Li; qingwenli1118@gmail.com

Received 24 July 2014; Accepted 23 October 2014

Academic Editor: Caiping Lu

Copyright (C) 2015 Qingwen Li et al. This is an open access article distributed under the Creative Commons Attribution License, which permits unrestricted use, distribution, and reproduction in any medium, provided the original work is properly cited.

\begin{abstract}
In the tunnel and underground space engineering, the blasting wave will attenuate from shock wave to stress wave to elastic seismic wave in the host rock. Also, the host rock will form crushed zone, fractured zone, and elastic seismic zone under the blasting loading and waves. In this paper, an accurate mathematical dynamic loading model was built. And the crushed zone as well as fractured zone was considered as the blasting vibration source thus deducting the partial energy for cutting host rock. So this complicated dynamic problem of segmented differential blasting was regarded as an equivalent elastic boundary problem by taking advantage of Saint-Venant's Theorem. At last, a 3D model in finite element software FLAC3D accepted the constitutive parameters, uniformly distributed mutative loading, and the cylindrical attenuation law to predict the velocity curves and effective tensile curves for calculating safety criterion formulas of surrounding rock and tunnel liner after verifying well with the in situ monitoring data.
\end{abstract}

\section{Introduction}

With the rapid infrastructure development in China, the improvement of control level on the blasting technique, and the well adaptability in various engineering, the blasting construction are used more and more widely; also, the drill and blast method has been becoming the most primary method in tunneling and underground space construction; in China, there are more than 95\% mountain tunnel constructions which adopt the drill and blast method [1]. Also, the blasting is producing huge help on the engineering yet generating many adverse effects on existing structures. Also, many scholars have done a lot of researches on adverse effects [2-4]. Hence, predicting the vibration safety criterion has become an important and effective method for analyzing the adverse effects. Jiang and Zhou used the safety criterion method to analyze tunnel liner structure [5]. Karadogan et al. gave a damage criteria norm for blast-induced ground vibrations in Turkey [6]. Yang et al. studied the safety distance for secondary shotcrete in Jinping-II deep-buried tunnels [7].
Though many works have been done by all the world scholars, the most attempts were based on the monitoring data to summarize the empirical equation [8-18], which is restricted for the real engineering blasting vibration. At the same time, some new methods are used to analyze the blasting problem, such as the soft computing method [19], artificial neural networks method [20], MEMS-based commutation module, [21] and RES-based model [22]. But it should be based on large number of in situ monitoring data, not considering the effect of vibration frequency and duration.

The numerical simulation has become an important prediction method in the engineering, due to its high accuracy and less cost, as well as the fast development computer technique, to make many scholar use such ads ANSYS/LSDYNA finite element software to solve the blasting vibration problems [23-29]. However, most models accepted the simplified triangle dynamic load, trapezoid dynamic load, or simplified data table which are not accurate enough for the blasting loading. 
In blasting, the gas pressure in hole reached 50 to 100 thousand times atmosphere. The high gas pressure could crush the host rock around blast hole to form the crushed zone. And because of higher dynamic compressive strength, the crushed zone will consume large partial energy to make the shock wave attenuate very fast. After propagating a distance, the pressure cannot crush the host rock any more, to make the shock wave attenuate as stress wave. Then the surrounding rock would suffer radial compression to generate a strong radial movement to lead the rock shell expansion to cause the circular tensile stress. Also, the tensile stress tends to be greater than critical dynamic tensile strength which is usually less than 1/10 compression strength of rock masses, to lead to the radial fractures formed. After those radial fractures connected with crushed zone, the blasting gas which looked like a wedge entered the radial fractures to make them enlarge. Hence, the fractured zone would be formed which also could consume some energy to make the vibration wave attenuate as elastic seismic wave whose impact region was the elastic seismic zone.

In this paper, the accurate mathematical model of blasting loading was established on the analysis of the blasting pressure change, the blast hole volume expansion, the fracture development, and the blasting gas motion. All the blasting energy transformed to the kinetic energy of the host rock without considering energy loss, this energy was used to form the crushed zone and fractured zone, and the residual energy was used to produce the vibration in elastic seismic zone to propagate out. So the crushed zone and fractured zone were also regarded as the blasting vibration source by taking advantage of the unified mechanical and continuum damage mechanics thus deducting this partial energy for cutting host rock, and regarding the vibration wave on the elastic seismic zone as the cylindrical elastic seismic wave to attenuate along with radius direction [30].

For the far field vibration analysis, the separate blasting loading of each hole could meet Saint-Venant's theorem to be regarded as the uniformly distributed loading on its own segmentation cutting zone. Hence the complicated dynamic problem in segmented differential blasting turned into an initial equivalent elastic boundary problem alongside the uniformly distributed and the attenuation law. At last, a $3 \mathrm{D}$ model in finite element software FLAC3D accepted the parameters to predict the velocity curve and effective tensile curve for confirming safety criterion after verifying well with the in situ monitoring data.

\section{Equivalent Boundary of Elastic Seismic Loading}

Based on above analysis, for the far field vibration, after a distance propagating, the blasting wave would attenuate as the elastic seismic wave, and this elastic seismic wave followed a circular attenuation law along the radius direction. Also, the crushed zone and fractured zone were considered as blasting vibration source boundary by taking advantage of continuum damage mechanics theory and unified constitutive theory [30].
2.1. Seismic Elastic Velocity. During the blasting, assuming the host rock as non-compressible linear media, and all the blasting energy would transform to kinetic energy of host rock without any energy loss. So, according to dynamic gradient theory in the semi-infinite medium, the formula of the velocity can be shown as [31]

$$
V=\sqrt{\frac{\rho_{0} q}{8 \rho_{r} v_{s}}} \frac{\bar{L}}{\bar{r} \sqrt{(\bar{r})^{2}+(\bar{L} / 2)^{2}}},
$$

where

$$
v_{s}=\ln \frac{\bar{L}+\sqrt{1+\bar{L}^{2}}}{-\bar{L}+\sqrt{1+\bar{L}^{2}}}, \quad \bar{L}=\frac{L_{0}}{2 r_{0}}, \quad \bar{r}=\frac{r}{2 r_{0}},
$$

where $V$ is the vibration rounded velocity, $\rho_{0}$ is the explosive density, $q$ is the blasting energy, $L_{0}$ is the charging length, $r_{0}$ is radius of blast hole, and $r$ is the propagated distance.

For a single blast hole in semi-infinite medium, the mainly destructional form of the crushed zone with the radius $r_{1}$ and for the fractured zone with radius $r_{2}$, so the formula can be expressed as [32]

$$
\begin{aligned}
& r_{1}=\left(\frac{\rho_{r} c_{p}^{2}}{5 \sigma_{c}}\right)^{1 / 2}\left(\frac{P}{\sigma_{*}}\right)^{1 / 4} r_{0}, \\
& r_{2}=\left[\frac{v P}{(1-v) \sigma_{t}}\right]^{1 / \alpha} r_{0},
\end{aligned}
$$

where $v$ is Poisson's ratio, $c_{p}$ is the P-wave of rock mass, $\sigma_{c}$ and $\sigma_{t}$ are, respectively, the dynamic compressive strength and dynamic tensile strength of rock, $\sigma_{*}$ is the static compressive strength, $P$ is the blasting loading on the blast hole wall, and $\alpha$ is the attenuation coefficient of blasting vibration wave.

In above,

$$
c_{p}^{2}=\frac{\lambda+2 G}{\rho_{r}}, \quad \lambda=\frac{2 G v}{1-2 v},
$$

where $G$ is the shear modulus and $\rho_{r}$ is the density of rock mass.

Experimental study showed that the radius of crushed zone is 3 to 5 times blast hole radius and 10 to 15 times for fractured zone [33].

2.2. Seismic Elastic Loading on Equivalent Boundary. For the elastic seismic loading, the attenuation functions of shock wave and stress wave with the time and displacement, to make the blasting loading $P(x, t)$ worked on the blast hole wall was shown as [34]

$$
P_{a}(x, t)=P(x, t)\left(\frac{r_{0}}{r}\right)^{\alpha},
$$

where $P_{a}(x, t)$ is the blasting loading after attenuating along with distance in radius and $\alpha$ is the attenuation coefficient of vibration wave; in above formula, for the shock wave

$$
\alpha=2+\frac{v}{1-v} \text {, and for stress wave } \alpha=2-\frac{v}{1-v} .
$$




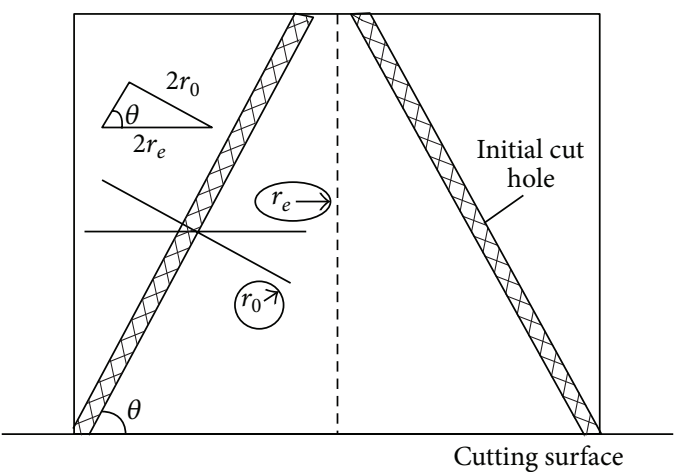

FIGURE 1: Initial cut hole with cutting surface.

For the underground space and tunneling blasting construction, there are, respectively, the initial cut hole, destruction rock hole, peripheral hole, and bottom hole arranged on the cutting surface, among, the initial cut holes were the inclined hole located in the center of cut surface, and the other holes were vertical hole surrounded the initial cut holes. Hence the blasting vibration must be a multiple and superimposed waves on cutting surface.

(1) The Equivalent Blasting Loading of Initial Cut Zone. According to the above formula, for elastic dynamic loading of single blast hole, for the initial cut hole with ignoring the overlapping influence and energy loss, the equivalent elastic loading can be shown as

$$
P_{e s}(x, t)=P(x, t)\left(\frac{r_{0}}{r_{1}}\right)^{2+v /(1-v)}\left(\frac{r_{1}}{r_{2}}\right)^{2-v /(1-v)},
$$

where $P_{e s}(x, t)$ is dynamic load of single initial cut hole.

Assuming the angle between initial cut hole and cut surface is $\theta$, so the projection of blast hole on the cut surface is ellipse with long radius $r_{e}$ and the short radius $r_{0}$ (the radius of blast hole), as shown in Figure 1.

From the above relationship, we can know $r_{e}=r_{0} / \sin \theta$. Usually, the initial cut hole was the first blasting segment, so the equivalent elastic dynamic load of initial cut section with considering the crushed zone and fractured zone as dynamic loading boundary was shown in Figure 2 .

The equivalent elastic loading of all the initial cut holes by taking advantage of Saint-Venant's principle was shown as

$$
P_{e}(x, t)=\frac{k_{1} S_{e}}{S_{e q}} P(x, t)\left(\frac{r_{0}}{r_{1}}\right)^{2+v /(1-v)}\left(\frac{r_{1}}{r_{2}}\right)^{2-v /(1-v)},
$$

where $P_{e}(x, t)$ is equivalent elastic loading of all the initial cut holes, $k_{1}$ is the number of holes, $S_{e}$ is the area of a single elliptic fractured zone with taking the 10 to 15 times blast hole's projection radius, and $S_{e q}$ is the area of whole initial cut section.

(2) The Equivalent Blasting Loading of Other Segments. Except the initial cut holes, there was a free face due to last segmented blasting for other segments. And the free face make this segmented blasting could cut the whole rock mass between

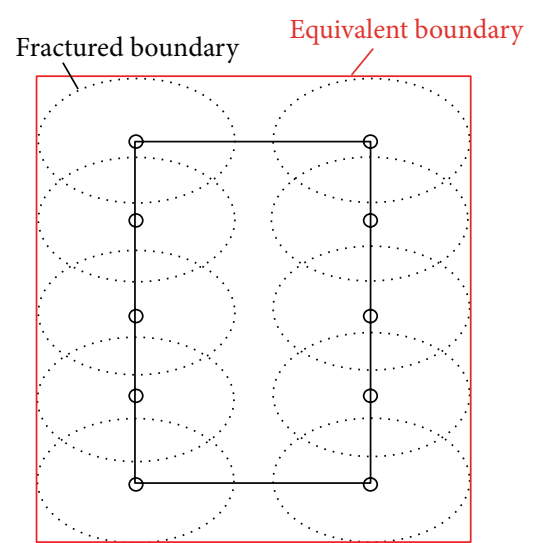

FIGURE 2: Equivalent boundary of initial cut zone.

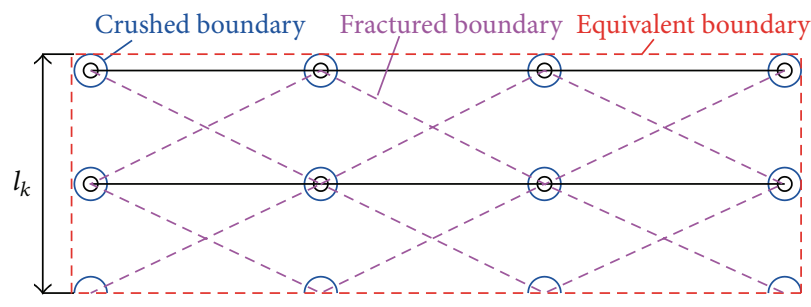

FIgURE 3: Equivalent boundary of other segments.

this segment and last segment, as shown in Figure 3. So taking $r_{2}=l_{k}$, the formula is carried out as below:

$$
P_{e}(x, t)=\frac{S_{0}}{S-S_{e q}} P(x, t)\left(\frac{r_{0}}{r_{1}}\right)^{2+v /(1-v)}\left(\frac{r_{1}}{l_{k}}\right)^{2-v /(1-v)},
$$

where $S_{0}$ is the area of a segmented blasting, $S$ is the area of whole cut surface, and $l_{k}$ is width of $k$ th segmented blasting.

Based on the time interval of two segments, the total equivalent elastic loading of other segments was shown as

$$
\begin{aligned}
P_{t}(x, t) & \\
& =\sum_{m=1}^{k=n} \frac{S_{0}}{S-S_{e q}} P\left(x, t+\tau_{k}\right)\left(\frac{r_{0}}{r_{1}}\right)^{2+v /(1-v)}\left(\frac{r_{1}}{l_{k}}\right)^{2-v /(1-v)},
\end{aligned}
$$

where $n$ is the number of segments and $\tau_{k}$ is the time interval between two segments.

\section{Continuum Damage Mechanics}

For the host rock of tunnel, there was a damage zone due to internal stress redistribution and fracture extension. This damage made constitutive parameter become lower, which also generated impact on vibration wave propagation. The Canadian scholars measured that the main fracture extension depth is $0.5 \mathrm{~m}$, and the maximum depth could reach $1.0 \mathrm{~m}$ with using in situ ultrasonic wave velocity testing technology [35]. So according to continuum damage mechanics theory, 
the effective stress under damage condition can be expressed as [36]

$$
\sigma_{i j}^{*}=\sigma_{i j}^{\prime}(1-D),
$$

where $\sigma_{i j}^{*}$ is the effective stress under damage condition, $\sigma_{i j}^{\prime}$ is effective stress of protolith, $D$ is the scalar of damage condition, which can be carried out by Mazar damage model with two scalars being, respectively, tensile damage $D_{t}$ and compression damage $D_{c}$, shown as [37]

$$
\begin{aligned}
& D_{c}\left(\varepsilon_{c}\right)=1-e^{-\alpha_{c}\left(\varepsilon_{c}-\varepsilon_{c 0}\right) / \varepsilon_{c 0}}, \\
& D_{t}\left(\varepsilon_{t}\right)=1-e^{-\alpha_{t}\left(\varepsilon_{t}-\varepsilon_{t 0}\right) / \varepsilon_{t 0}},
\end{aligned}
$$

where $\alpha_{c}$ and $\alpha_{t}$ are, respectively, compression and tensile coefficients, which depended on the material properties, for the rock, their value is usually 0.5 , and $\varepsilon_{c 0}$ and $\varepsilon_{t 0}$ are, respectively, uniaxial compression and uniaxial tensile critical strain value. As shown below:

$$
\begin{aligned}
& \varepsilon_{c}=\sqrt{\sum_{i=1,3}\left(\varepsilon_{i}^{-}\right)^{2}}, \\
& \varepsilon_{t}=\sqrt{\sum_{i=1,3}\left(\varepsilon_{i}^{+}\right)^{2}},
\end{aligned}
$$

$\varepsilon_{i}^{-}, \varepsilon_{i}^{+}$are, respectively, the negative and positive strains.

So, the damage scalar is the superposition of compression and tensile:

$$
\begin{gathered}
D=A_{c} D_{c}+A_{t} D_{t}, \quad A_{c}+A_{t}=1, \\
A_{c}=\sum_{i=1,3} \frac{H_{i}\left[\varepsilon_{i}^{-}\left(\varepsilon_{i}^{-}+\varepsilon_{i}^{+}\right)\right]}{\bar{\varepsilon}_{i}^{2}}, \\
A_{t}=\sum_{i=1,3} \frac{H_{i}\left[\varepsilon_{i}^{+}\left(\varepsilon_{i}^{-}+\varepsilon_{i}^{+}\right)\right]}{\bar{\varepsilon}_{i}^{2}},
\end{gathered}
$$

where $\bar{\varepsilon}_{i}^{2}=\sum_{i=1,3}\left(\varepsilon_{i}^{-}+\varepsilon_{i}^{+}\right)^{2}$ is the effective strain, and when $x<0, H[x]=0$, and when $x>0, H[x]=x$.

Based on above analysis, in the damage host rock, the formula of Young modulus between damage rock and original rock is

$$
E^{d}=E_{0}(1-D),
$$

where $E^{d}$ is the Young modulus under damage rock and $E_{0}$ is Young modulus under original rock.

\section{Equivalent Process of Blasting Loading}

After blasting, the dynamic loading on the blast hole wall can make the volume of blast hole enlarged and the fracture expanded; also, the gas pressure and dynamic loading must be reduced with volume enlargement. At last, the explosion gas rapidly overflowed and the applied force decayed to zero with fracture development to connect each other.
Based on blasting mechanism, the process of blasting loading can be divided into four stages.

(1) The first stage: the dynamic loading will increase with time till reaching the peak intensity of blasting.

(2) The second stage: the blasting pressure will be reduced by the fracture expending, the fillings moving, and the volume increasing before the filling was ejected from the hole.

(3) The third stage: the explosive gas erupts quickly from the blast hole to lead to lower pressure after the filling was ejected.

(4) The fourth stage: the explosive gas rapidly overflowed and the applied force decayed to zero when fractures develop to connect together.

4.1. The First Stage of Blasting. The dynamic loading will increase with time till reaching the peak intensity of blasting when the detonation gas wave propagated to the bottom section of blast hole after exploding. Many research works show that the initial peak blasting loading must have relationship to detonation wave pressure, and according to the ChapmanJouguet model, the detonation wave pressure in an explosion can be guided by the widely known equation [34]

$$
P_{D}=\frac{1}{\gamma+1} \rho_{0} V_{D}
$$

where $P_{D}$ is the largest detonation wave pressure, $\rho_{0}$ is the density of explosive, $V_{D}$ is detonation velocity, and $\gamma$ is the ratio of the specific heats for the detonation gases; in this formula $\gamma=3.0$.

The initial explosion pressure which was the explosion gas acted on the blast hole wall just after detonation is approximately the half of the detonation pressure for the coupled charge:

$$
P_{1}=\frac{\rho_{0} V_{D}}{2(\gamma+1)} .
$$

For decoupled charges, the initial explosion pressure also had the relationship to the proportion between the blast hole diameter and the charge diameter, so the formula is

$$
P_{1}=\frac{\rho_{0} V_{D}}{2(\gamma+1)}\left(\frac{a}{b}\right)^{2 \gamma}
$$

where $a$ is the charge diameter and $b$ is the blast hole diameter.

The rising time of loading was shown as

$$
t_{1}=\frac{L}{V_{D}},
$$

where $L$ is the length of blast hole.

4.2. The Second Stage of Blasting. The blasting pressure will reduce with the fracture expending, the filling moving, and the volume increasing of blast hole before the filling was 


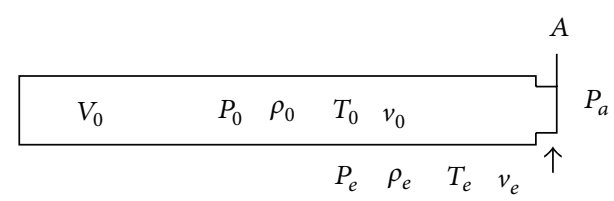

FIgURE 4: The equivalent structure of third stage.

ejected from the hole. So the volume of detonation gas with time can be expressed as

$$
\Delta V(t)=2 \pi r(t) u(t) L d t+2 L \int_{0}^{L_{a}} \omega(\eta) d \eta+\frac{1}{4} \pi r(t)^{2} y(t),
$$

where $r(t)$ is the blast hole radius with time, $u(t)$ is the expansion velocity of blast hole wall, $\omega(\eta)$ is the width of fracture, and $y(t)$ is displacement of filling with time.

According to gas law, gas pressure with volume changed in detonation cavity can be shown as [5]

$$
P_{2}=A\left(1-\frac{\omega}{R_{1} V}\right) e^{-R_{1} V}+B\left(1-\frac{\omega}{R_{2} V}\right) e^{-R_{2} V}+\frac{\omega E_{0}}{(V)} .
$$

Put the formula (21) into formula (22):

$$
\begin{aligned}
P_{2}(t)= & A\left(1-\frac{\omega}{R_{1}\left(V_{0}+\Delta V(t)\right)}\right) e^{-R_{1}\left(V_{0}+\Delta V(t)\right)} \\
& +B\left(1-\frac{\omega}{R_{2}\left(V_{0}+\Delta V(t)\right)}\right) e^{-R_{2}\left(V_{0}+\Delta V(t)\right)} \\
& +\frac{\omega E_{0}}{\left(V_{0}+\Delta V(t)\right)}
\end{aligned}
$$

where $V_{0}$ is the initial volume of blast hole, $A, B, R_{1}, R_{2}$, and $\omega$ are all the explosive material parameter, and $E_{0}$ is initial energy of explosive.

4.3. The Third Stage of Blasting. The explosive gas erupts quickly out from the blast hole to lead to pressure getting lower after the filling was ejected or no filling blasting; according to gas dynamics theory, the blast hole in this period can be looked at as a bottle structure which follows the next assumptions, (a) because of the volume of blast hole was enlarged in last stage, which make the section of exit is smaller than inside, the shape of blast hole looks like a bottle; (b) because of very short time of reaction and better heatinsulating property of rock, the whole process are assumed as adiabatic process; (c) because of the very slow speed of volume expansion during last stage, the initial velocity of gas is zero at the beginning of this stage, so $v_{0}=0$, as shown in Figure 4.

In Figure $4, V_{0}, P_{0}, \rho_{0}, T_{0}$, and $v_{0}$ are, respectively, the initial volume, pressure, density, temperature, and velocity. Also, $P_{e}, \rho_{e}, T_{e}$, and $v_{e}$ are, respectively, the pressure, density, temperature, and velocity at the section of exit.
For this bottle structure, the inner pressure change of blast hole had the relationship with gas erupted statement; when $P_{\mathrm{cr}} / P_{a}=1$, the exit statement was critical condition, and the velocity of gas erupted was sound velocity; when $P_{\mathrm{cr}} / P_{a}<1$, the exit statement was subcritical condition, and the pressure at the exit was equal to air pressure $P_{e}=P_{a}$; when $P_{\mathrm{cr}} / P_{a}>$ 1 , the exit statement was supercritical statement, and there was congested phenomenon at exit to make the velocity of gas also the sound velocity, $M a=v_{\text {cr }} / v_{s}=1$, where $P_{\text {cr }}, v_{\text {cr }}$ are, respectively, critical statement of pressure and velocity.

According to isentropic gas formula, $P_{\mathrm{cr}} / P_{0}=\left(T_{\mathrm{cr}} /\right.$ $\left.T_{0}\right)^{\gamma /(\gamma-1)}=(2 /(\gamma+1))^{\gamma /(\gamma-1)}$ to determine critical pressure value $P_{\mathrm{cr}}$, where $T_{\mathrm{cr}}$ is the critical temperature, $\gamma$ is the specific heat ratio of the gas, and $R=297 \mathrm{~J} /(\mathrm{kg} \cdot \mathrm{K})$ is the gas constant, so

$$
\frac{P_{\text {cr }}}{P_{0}}=0.3536
$$

Usually, the gas pressure in blast hole can reach $p_{0}=(50000 \sim$ 10000) $p_{a}$, so the critical pressure $p_{\mathrm{cr}} \gg p_{a}$, which was supercritical statement to make the velocity of erupted gas be sound velocity.

Based on above analysis, the gas flow formula at the supercritical statement was

$$
q_{\mathrm{mcr}}=A\left(\frac{2}{\gamma+1}\right)^{(\gamma+1) / 2(\gamma-1)} \sqrt{\gamma P_{0} \rho_{0}} .
$$

From time $t$ to $t+d t$, based on the first law of thermodynamics with taking advantage of adiabatic process of gas in blast hole,

$$
\frac{P}{\rho^{\gamma}}=\text { const. }
$$

So,

$$
\frac{P_{e}(t)}{\rho_{e}(t)^{\gamma}}=\frac{p_{e}(t+d t)}{\rho_{e}(t+d t)^{\gamma}}
$$

Put the formula (25) into formula (27):

$$
\frac{P_{e}(t)}{\rho_{e}(t)^{\gamma}}=\frac{P_{e}(t+d t)}{\left(\rho_{e}(t)-\left(A / V_{0}\right)(2 /(\gamma+1))^{(\gamma+1) / 2(\gamma-1)} \sqrt{\gamma P_{0} \rho_{0}} d t\right)^{\gamma}} .
$$

So,

$$
\begin{aligned}
& P_{e}(t+d t) \\
& \quad=P_{e}(t)\left(\frac{\rho_{e}(t)-(A / V)(2 /(\gamma+1))^{(\gamma+1) / 2(\gamma-1)} \sqrt{\gamma P_{0} \rho_{0}} d t}{\rho_{e}(t)}\right)^{\gamma} .
\end{aligned}
$$

So, the formula of gas pressure change was

$$
\begin{aligned}
P_{3}(t+d t) & =P_{e}(t+d t) \\
& =P_{e}(t)\left(1-\frac{A}{V}\left(\frac{2}{\gamma+1}\right)^{(\gamma+1) / 2(\gamma-1)} \frac{\sqrt{\gamma P_{0} \rho_{0}}}{\rho_{e}(t)} d t\right)^{\gamma} .
\end{aligned}
$$




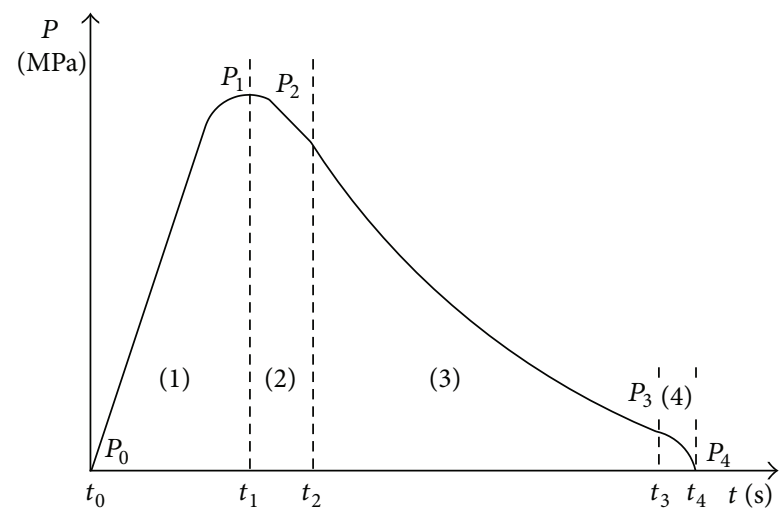

FIGURE 5: Blasting loading model.

4.4. The Fourth Stage of Blasting. The explosive gas rapidly overflows and the applied force decays to zero fast with fractures development to connect.

4.5. The Discipline of Loading. According the above separated analysis of blasting process, the blasting loading curve was shown as in Figure 5.

In Figure $5, t_{0}$ is the beginning of blasting time, so $t_{0}=$ 0 ; the initial dynamic loading $P_{0}=0 ; t_{1}$ is the maximum blasting loading time, $P_{1}$ is the maximum blasting loading, $t_{2}$ is the time of fillings ejected, $P_{2}$ is the loading on the blast hole wall at that time, $t_{3}$ is the time just before fractures connect each other, $P_{3}$ is the loading on the blast hole wall at that time, $t_{4}$ is the end time of blasting, and $P_{4}=0$ is the gas pressure.

\section{Project of Case Study}

5.1. Engineering Introduction. The Chen-Chi West Connection Line Highway Tunnel, which was designed as a separate double tunnel each containing two lanes, was chosen as the case to be studied. The lengths of two tunnels are $1075 \mathrm{~m}$ and $1185 \mathrm{~m}$, and the distance between them is between $18 \mathrm{~m}$ and $20 \mathrm{~m}$. The cavern on the foothill region is $14 \mathrm{~m}$ wide and $12 \mathrm{~m}$ high. In this tunnel blasting, No. 2 rock emulsion explosive with diameter is $32 \mathrm{~mm}$, length is $200 \mathrm{~mm}$, and weight is $150 \mathrm{~g}$ was used. And positive multistage differential blasting method was taken by initial cut holes, destruction rock holes, peripheral holes, and bottom holes on the cutting surface. In working surface the distance between the holes was from $0.5 \mathrm{~m}$ to $0.7 \mathrm{~m}$, the depth of the blast hole was $3.0 \mathrm{~m}$, the charge length was $2.5 \mathrm{~m}$ without fillings, and the detonating cord across through the whole hole from opening to bottom. The blasting parameters were shown in Table 1 , and the form of segments was shown in Figure 6 and interval time was shown in Table 2.

5.2. Constitutive Parameter. The formation lithology rock in the tunnel area is conglomerate, which belongs to the late Jurassic conglomerate, color is purple and structure is gravel with the diameter from $2 \mathrm{~mm}$ to $60 \mathrm{~mm}$, and the gravels are cemented together with fillings to form the thick block layer. The compositions of the gravels are andesite, welded

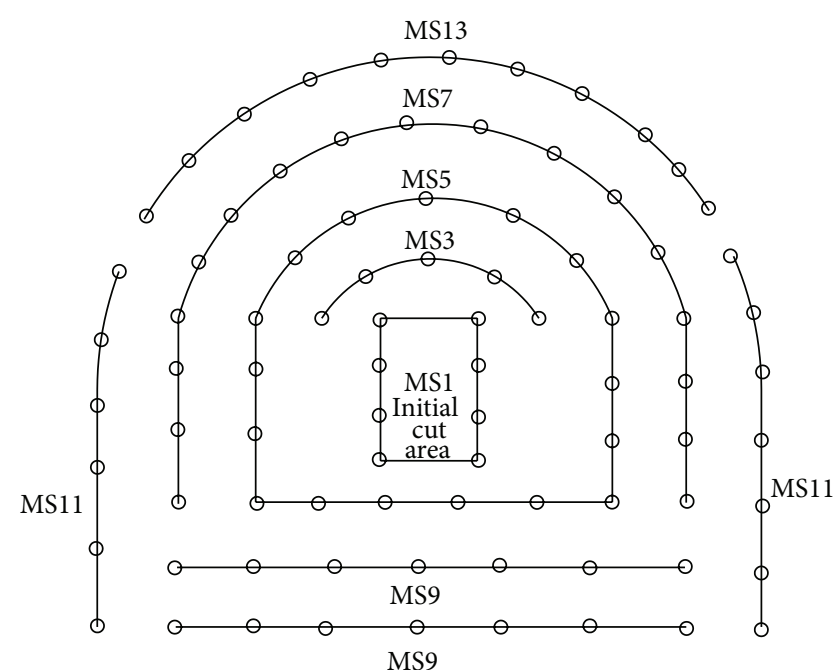

FIGURE 6: Blasting segmented situation.

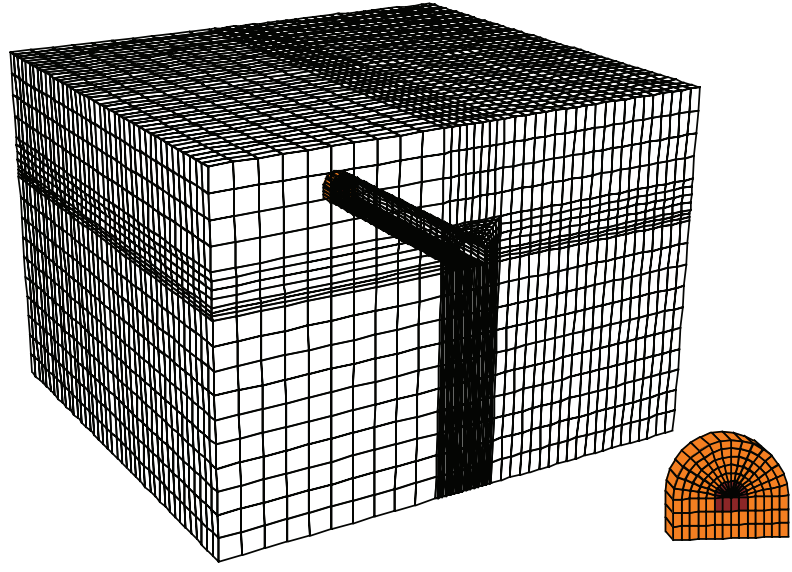

Block group

Other blasting hole

Initial cut zone

FIGURE 7: 3D model in numerical simulation.

tuff, rhyolite, and siliceous rocks, and for the fillings they are debris of rock, fine sand, quartz, feldspar, and some other stable mineral sand. The constitutive parameters are shown in Table 3.

\section{Numerical Simulation Analysis}

6.1. Simulation Model. Based on the actual engineering geology and structures, a 3D model was built in the finite element software of FLAC3D to accept the constitutive parameters, blasting load, and wave propagation parameters, as shown in Figure 7. The geometrical dimensions are length $228 \mathrm{~m}$ ( $X$ direction), width $203 \mathrm{~m}$ ( $Y$ direction), and height $159 \mathrm{~m}$ ( $Z$ direction). The finite element mesh consists of 386527 nodes and 372200 elements. And for the blasting zone, the group was between $100 \mathrm{~m}$ and $103 \mathrm{~m}$ ( $Y$ direction) after the cutting length $100 \mathrm{~m}$, the initial cut hole zone was meshed 
TABLE 1: Blasting parameters.

\begin{tabular}{lcccc}
\hline Charge diameter $(\mathrm{mm})$ & Blast hole diameter $(\mathrm{mm})$ & Holes number & Explosive density $\left(\mathrm{kg} / \mathrm{m}^{3}\right)$ & Detonation velocity $(\mathrm{m} / \mathrm{s})$ \\
\hline 32 & 40 & 80 & 1000 & 3200
\end{tabular}

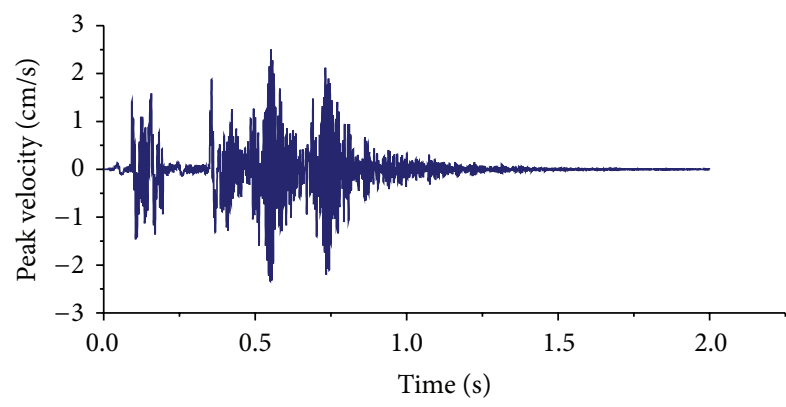

FIGURE 8: Simulated velocity curves in surrounding rock.

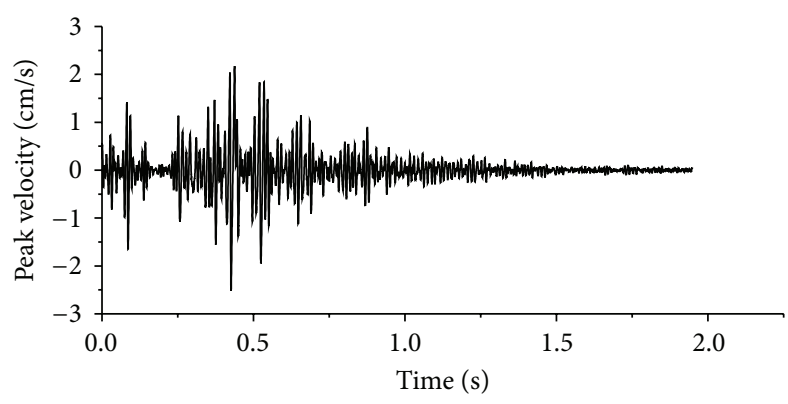

FIGURE 9: Monitored velocity curves in surrounding rock.

TABLE 2: The time interval of every multistage.

\begin{tabular}{ccccccc}
\hline MS1 & MS3 & MS5 & MS7 & MS9 & MS11 & MS13 \\
\hline $0 \mathrm{~ms}$ & $50 \mathrm{~ms}$ & $110 \mathrm{~ms}$ & $200 \mathrm{~ms}$ & $310 \mathrm{~ms}$ & $460 \mathrm{~ms}$ & $650 \mathrm{~ms}$ \\
\hline
\end{tabular}

as 192 elements (brownish zone) and other worked zone was meshed as 606 elements (orange zone), also, as shown in Figure 7.

6.2. Dynamic Loading in Simulation. For the decoupled charge blasting, every stage pressure and arrival time were calculated by using above formulas. The detail values were shown in Table 4.

In the numerical simulation, it is difficult to determine the dumping of the rock mass directly, so, the field monitoring and calculation is necessary; in this paper, the dumping which was input into model was 0.015 based on the field monitoring and calculation repeatedly.

6.3. Verification of Simulation. In this simulation, the solve time was set to $2 \mathrm{~s}$, and after 1284933 calculation steps, the curves of velocity were predicted from the model compared with 9 times field monitoring data at the same location. The simulation data and monitoring data were shown in Table 5, and the typical velocity curves were shown in Figures 8 and 9.

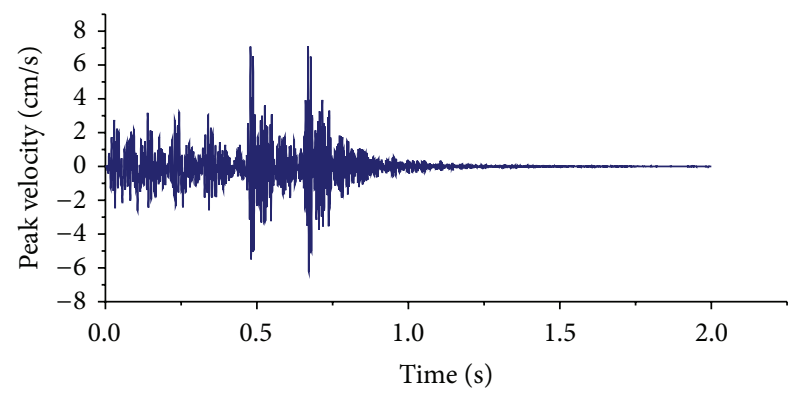

Figure 10: Velocity curves in surrounding rock.

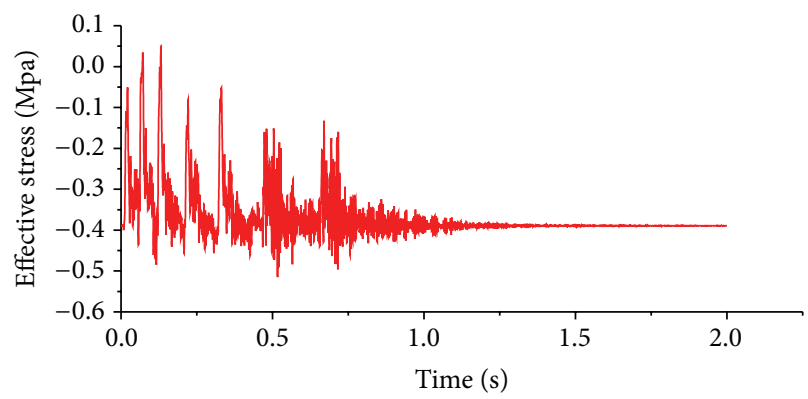

FIGURE 11: Tensile stress curves in surrounding rock.

As shown in Figure 8, the predicted peak velocity was $2.505 \mathrm{~cm} / \mathrm{s}$ compared with monitored peak velocity $2.51 \mathrm{~cm} / \mathrm{s}$ which was obtained from Figure 9, so, the error rate is $2 \%$; also, for those two curves, they had similar arrival time from $0.3 \mathrm{~s}$ to $0.7 \mathrm{~s}$. From the error rate and similar arrival time, the simulation result in the surrounding rock was accurate enough for analysis. Also, for the other group data in Table 4, the error rates are from $0.5 \%$ to $23.1 \%$, which all show that the simulation had the higher accurate results.

6.4. Predicted Results Analysis. After the simulation, the velocity curves and effective tensile stress curves with the distances $10 \mathrm{~m}, 20 \mathrm{~m}, 30 \mathrm{~m}, 50 \mathrm{~m}$, and $80 \mathrm{~m}$ from the blasting point in surrounding rock and tunnel liner were obtained. The typical curves were shown in Figures 10-13.

For the surrounding rock, as shown in Figure 10, the peak velocity is 7.099. And the maximum effective tensile stress is 0.4502, which was shown in Figure 11. Also, for the tunnel liner, it is easy to learn that the peak velocity is 2.719 and maximum effective tensile stress is 0.7434 from Figures 12 and 13.

6.5. Conforming with Safety Criterion. The peak velocity and maximum effective stress can be obtained from the simulated model, which were shown in Table 6. 
TABle 3: Constitutive parameters of the rock.

\begin{tabular}{lcccccc}
\hline $\begin{array}{l}\text { Density } \\
\left(\mathrm{Kg} / \mathrm{m}^{3}\right)\end{array}$ & $\begin{array}{c}\text { Compressive } \\
\text { strength } \\
(\mathrm{MPa})\end{array}$ & $\begin{array}{c}\text { Tensile } \\
\text { strength } \\
(\mathrm{MPa})\end{array}$ & $\begin{array}{c}\text { Poisson's } \\
\text { ratio }\end{array}$ & $\begin{array}{c}\text { Cohesion } \\
(\mathrm{MPa})\end{array}$ & $\begin{array}{c}\text { Friction angle } \\
(\mathrm{MPa})\end{array}$ & $\begin{array}{c}\text { Compressive } \\
\text { hardening } \\
\text { coefficient } \\
(\mathrm{MPa})\end{array}$ \\
\hline 2820 & 75.5 & 3.0 & 0.2 & 4.5 & 38 & $\begin{array}{c}\text { Tensile } \\
\text { hardening } \\
\text { coefficient } \\
(\mathrm{MPa})\end{array}$ \\
\hline
\end{tabular}

TABLE 4: The detail value of every stage pressure and arrival time.

\begin{tabular}{lccccccc}
\hline & $P_{D}(\mathrm{MPa})$ & $P_{L}(\mathrm{MPa})$ & $P_{0}(\mathrm{MPa})$ & $P_{1}(\mathrm{MPa})$ & $P_{2}(\mathrm{MPa})$ & $P_{3}(\mathrm{MPa})$ & $P_{4}(\mathrm{MPa})$ \\
\hline Initial cut zone & 2560 & 335.5 & 0 & 18.73 & 18.73 & 2.02 & 0 \\
Other zones & 2560 & 335.5 & 0 & 34.22 & 34.22 & 6.45 & 0 \\
Arrival time (s) & & & $t_{0}=0$ & $t_{1}=0.01$ & $t_{2}=0.01$ & $t_{3}=0.122$ & $t_{4}=0.122$ \\
\hline
\end{tabular}

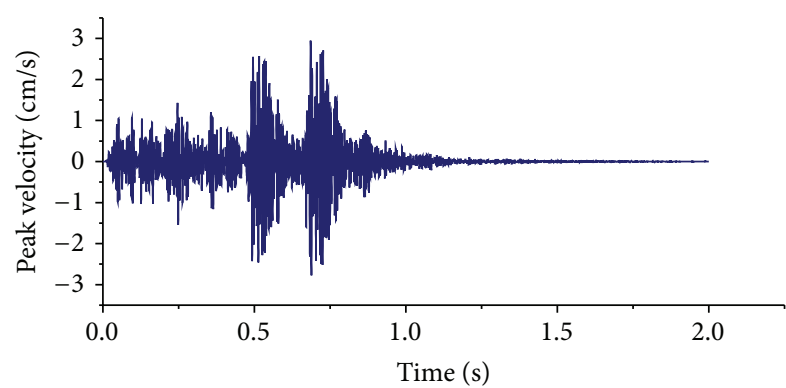

FIGURE 12: Velocity curves in tunnel liner.

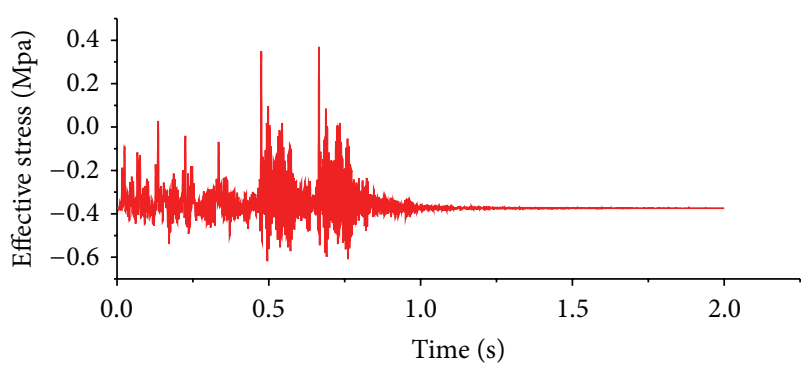

FIgURE 13: Tensile stress curves in tunnel liner.

Summarizing data in Table 6, the relationships between the effective tensile stress and peak velocity curves are, respectively, the safety criterion for the surrounding rock and tunnel liner, which were shown in Figures 14 and 15.

As shown in Figure 14, the safety criterion formula of the surrounding rock was

$$
\sigma_{t}=0.0363(\mathrm{PPV})^{2}-0.25 \mathrm{PPV}+0.4878, \quad R^{2}=0.991 .
$$

In this case study, the rock dynamic tensile strength is $4 \mathrm{MPa}$, so after calculating, when the PPV in the surrounding rock at the junction of tunnel arch and wall reaches $13.865 \mathrm{~cm} / \mathrm{s}$, the effective tensile stress will approach the maximum tensile strength.

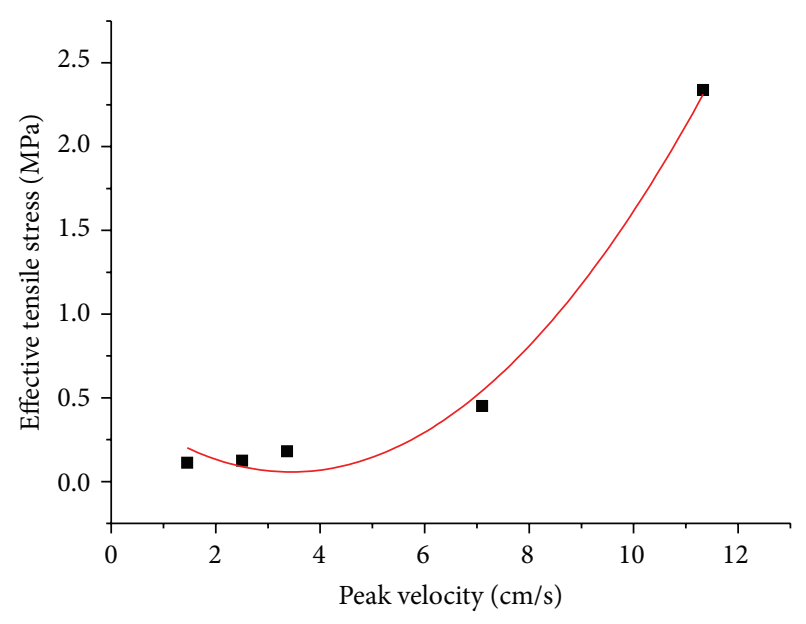

FIGURE 14: Safety criterion in surrounding rock.

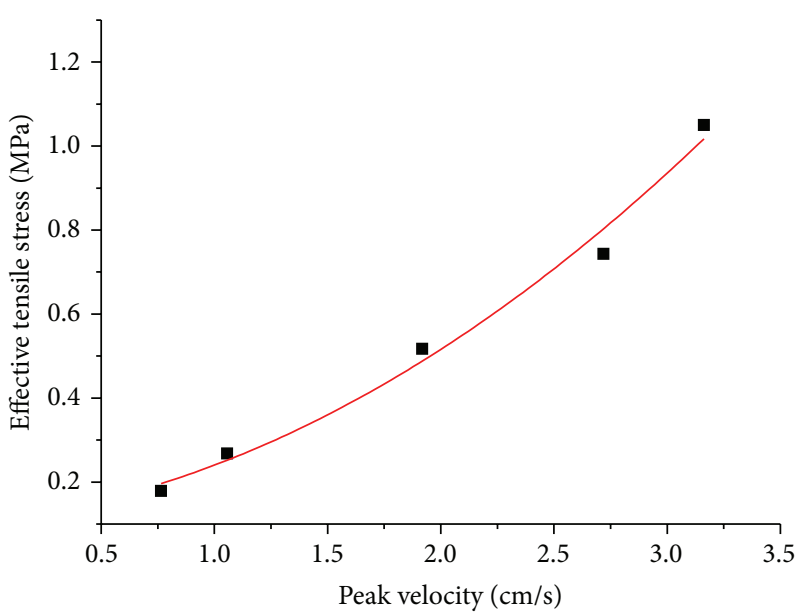

FIGURE 15: Safety criterion in tunnel liner.

As shown in Figure 15, the safety criterion formula was

$\sigma_{t}=0.0721(\mathrm{PPV})^{2}+0.0593 \mathrm{PPV}+0.1089, \quad R^{2}=0.988$. 
TABLE 5: The simulation and monitoring data of blasting vibration.

\begin{tabular}{|c|c|c|c|c|c|}
\hline Date & $\begin{array}{c}\text { Total charge } \\
(\mathrm{kg})\end{array}$ & Distance (m) & $\begin{array}{c}\text { Measured vertical PPV } \\
(\mathrm{cm} / \mathrm{s})\end{array}$ & $\begin{array}{l}\text { Predicted vertical PPV } \\
(\mathrm{cm} / \mathrm{s})\end{array}$ & Error rate (\%) \\
\hline 2013.5.18 & 240 & 64.3 & 1.263 & 1.293 & +2.3 \\
\hline 2013.5.22 & 240 & 58.8 & 1.519 & 1.644 & +8.2 \\
\hline 2013.5.24 & 240 & 57.2 & 1.705 & 1.771 & +3.8 \\
\hline 2013.5.27 & 240 & 54.8 & 1.999 & 1.998 & -0.5 \\
\hline 2013.6 .02 & 240 & 50.0 & 2.505 & 2.510 & +2 \\
\hline 2013.6 .03 & 240 & 53.2 & 2.248 & 2.176 & -3.2 \\
\hline 2013.6.11 & 240 & 57.2 & 2.304 & 1.771 & -23.1 \\
\hline 2013.6.12 & 240 & 58.8 & 1.582 & 1.641 & +3.7 \\
\hline 2013.6.14 & 240 & 62.3 & 1.747 & 1.403 & -19.6 \\
\hline
\end{tabular}

TABLE 6: Safety criterion data.

\begin{tabular}{|c|c|c|c|c|}
\hline \multirow[b]{2}{*}{ Distance $(\mathrm{m})$} & \multicolumn{2}{|c|}{ Surrounding rock } & \multicolumn{2}{|c|}{ Tunnel liner } \\
\hline & $\begin{array}{l}\text { Peak velocity } \\
(\mathrm{cm} / \mathrm{s})\end{array}$ & $\begin{array}{l}\text { Maximum effective } \\
\text { tensile stress ( } \mathrm{MPa})\end{array}$ & $\begin{array}{l}\text { Peak velocity } \\
(\mathrm{cm} / \mathrm{s})\end{array}$ & $\begin{array}{l}\text { Maximum effective } \\
\text { tensile stress (MPa) }\end{array}$ \\
\hline 10 & 11.33 & 2.337 & 3.162 & 1.050 \\
\hline 20 & 7.099 & 0.4502 & 2.719 & 0.7434 \\
\hline 30 & 3.370 & 0.1795 & 1.918 & 0.5172 \\
\hline 50 & 2.505 & 0.1233 & 1.057 & 0.2677 \\
\hline 80 & 1.455 & 0.1111 & 0.7643 & 0.1784 \\
\hline
\end{tabular}

Also, for the tunnel liner, because there was a damage zone caused by excavated stress resilience and before blasts, the damage scale was $D=0.2$ which was calculated by Mazar damage model based on the field fracture surveyed, so the safety criterion formula of the damage tunnel liner is

$$
\sigma_{t}^{*}=\frac{0.0721(\mathrm{PPV})^{2}+0.0593 \mathrm{PPV}+0.1089}{(1-D)}
$$

The damage dynamic tensile strength was $3.2 \mathrm{MPa}$ with the damage scale of $D=0.2$, so, when the PPV in the tunnel linear at the junction of tunnel arch and wall reaches $6.213 \mathrm{~cm} / \mathrm{s}$, the effective tensile stress will approach the maximum tensile strength.

\section{Conclusion}

For the far field vibration analysis, based on the unified theory, the crushed zone and fractured zone can be regarded as blasting vibration source. Also, the wave propagation was essentially elastic. It was proved to be very accurate after comparing between the simulated velocity curves and the field monitoring data.

The accurate mathematic loading model was carried out by the analysis of the blasting pressure change, blast hole volume expansion, the fracture development, and the blasting gas motion; after well verification, this dynamic loading curve was more realistic and more accurate to the real loading, than other simplified loadings.

For the far field vibration analysis, the separated blasting loadings of each hole were regarded as uniformly distributed loading on its own segmented zone by taking advantage of
Saint-Venant theorem; it also met the requirement of analysis by comparing the monitoring data.

Based on the predicted velocity curves and effective tensile stress curves in surrounding rock and tunnel linear, the safety criterion field can be carried out to analyze the safety and stability of every point in field. And through adopting the continuum damage mechanics theory, the safety criterion of tunnel linear was more corresponding to the real situation.

\section{Conflict of Interests}

The authors declare that there is no conflict of interests regarding the publication of this paper.

\section{Acknowledgments}

This work has been supported by the research on the characteristics of rock high strain rate under dynamic load, NSFC (Natural Science Foundation of China, no. 51474016). Also, thanks are to Dr. Ming Cui and Dr. Miao Li for help in gathering the monitoring data.

\section{References}

[1] W.-B. Lu, Y. Luo, M. Chen, and D.-Q. Shu, "An introduction to Chinese safety regulations for blasting vibration," Environmental Earth Sciences, vol. 67, no. 7, pp. 1951-1959, 2012.

[2] D.-N. Lin, "The mitigation negative effect of tunnel-blastinginduced vibrations on constructed tunnel and buildings," Journal of Coal Science and Engineering, vol. 17, no. 1, pp. 28-33, 2011. 
[3] F. Ji, J. Lu, Y. Shi, and C. Zhou, "Mechanical response of surrounding rock of tunnels constructed with the TBM and drill-blasting method," Natural Hazards, vol. 66, no. 2, pp. 545556, 2013.

[4] M. Monjezi, H. A. Mohamadi, B. Barati, and M. Khandelwal, "Application of soft computing in predicting rock fragmentation to reduce environmental blasting side effects," Arabian Journal of Geosciences, vol. 7, no. 2, pp. 505-511, 2014.

[5] N. Jiang and C. Zhou, "Blasting vibration safety criterion for a tunnel liner structure," Tunnelling and Underground Space Technology, vol. 32, pp. 52-57, 2012.

[6] A. Karadogan, A. Kahriman, and U. Ozer, "A new damage criteria norm for blast-induced ground vibrations in Turkey," Arabian Journal of Geosciences, vol. 7, no. 4, pp. 1617-1626, 2014.

[7] J. H. Yang, W. B. Lu, Z. G. Zhao, P. Yan, and M. Chen, "Safety distance for secondary shotcrete subjected to blasting vibration in Jinping-II deep-buried tunnels," Tunnelling and Underground Space Technology, vol. 43, pp. 123-132, 2014.

[8] A. Ansell, "In situ testing of young shotcrete subjected to vibrations from blasting," Tunnelling and Underground Space Technology, vol. 19, no. 6, pp. 587-596, 2004.

[9] M. Khandelwal, "Blast-induced ground vibration prediction using support vector machine," Engineering with Computers, vol. 27, no. 3, pp. 193-200, 2011.

[10] Q. Liang, Y. An, L. Zhao, D. Li, and L. Yan, "Comparative study on calculation methods of blasting vibration velocity," Rock Mechanics and Rock Engineering, vol. 44, no. 1, pp. 93-101, 2011.

[11] J.-H. Shin, H.-G. Moon, and S.-E. Chae, "Effect of blast-induced vibration on existing tunnels in soft rocks," Tunnelling and Underground Space Technology, vol. 26, no. 1, pp. 51-61, 2011.

[12] R. Nateghi, "Prediction of ground vibration level induced by blasting at different rock units," International Journal of Rock Mechanics \& Mining Sciences, vol. 48, no. 6, pp. 899-908, 2011.

[13] M. Rezaei, M. Monjezi, S. G. Moghaddam, and F. Farzaneh, "Burden prediction in blasting operation using rock geomechanical properties," Arabian Journal of Geosciences, vol. 5, no. 5, pp. 1031-1037, 2012.

[14] K. Dey and V. M. S. R. Murthy, "Prediction of blast-induced overbreak from uncontrolled burn-cut blasting in tunnels driven through medium rock class," Tunnelling and Underground Space Technology, vol. 28, no. 1, pp. 49-56, 2012.

[15] Z. Wang, C. Fang, Y. Chen, and W. Cheng, "A comparative study of delay time identification by vibration energy analysis in millisecond blasting," International Journal of Rock Mechanics and Mining Sciences, vol. 60, pp. 389-400, 2013.

[16] Q. Liang, J. Li, D. Li, and E. Ou, "Effect of blast-induced vibration from new railway tunnel on existing adjacent railway tunnel in Xinjiang, China," Rock Mechanics and Rock Engineering, vol. 46, no. 1, pp. 19-39, 2013.

[17] H. Fu, L. N. Y. Wong, Y. Zhao, Z. Shen, C. Zhang, and Y. $\mathrm{Li}$, "Comparison of excavation damage zones resulting from blasting with nonel detonators and blasting with electronic detonators," Rock Mechanics and Rock Engineering, vol. 47, no. 2, pp. 809-816, 2014.

[18] L. Ahmed and A. Ansell, "Vibration vulnerability of shotcrete on tunnel walls during construction blasting," Tunnelling and Underground Space Technology, vol. 42, pp. 105-111, 2014.

[19] M. Khandelwal, D. L. Kumar, and M. Yellishetty, "Application of soft computing to predict blast-induced ground vibration," Engineering with Computers, vol. 27, no. 2, pp. 117-125, 2011.
[20] M. Monjezi, M. Ghafurikalajahi, and A. Bahrami, "Prediction of blast-induced ground vibration using artificial neural networks," Tunnelling and Underground Space Technology, vol. 26, no. 1, pp. 46-50, 2011.

[21] J. Kim, S. Kwon, S. Park, and Y. Kim, "A MEMS-based commutation module with vibration sensor for wireless sensor network-based tunnel-blasting monitoring," KSCE Journal of Civil Engineering, vol. 17, no. 7, pp. 1644-1653, 2013.

[22] F. Faramarzi, M. A. E. Farsangi, and H. Mansouri, "An RESbased model for risk assessment and prediction of backbreak in bench blasting," Rock Mechanics and Rock Engineering, vol. 46, no. 4, pp. 877-887, 2013.

[23] M. Sazid and T. N. Singh, "Two-dimensional dynamic finite element simulation of rock blasting," Arabian Journal of Geosciences, vol. 6, no. 10, pp. 3703-3708, 2013.

[24] X. Xia, H. B. Li, J. C. Li, B. Liu, and C. Yu, "A case study on rock damage prediction and control method for underground tunnels subjected to adjacent excavation blasting," Tunnelling and Underground Space Technology, vol. 35, pp. 1-7, 2013.

[25] S. Sun, L. Yue, J. Wu, J. Liu, and J. Wei, "Case study on influence of step blast-excavation on support systems of existing service tunnel with small interval," Advances in Mechanical Engineering, vol. 2013, Article ID 257457, 13 pages, 2013.

[26] J. Yang, W. Lu, M. Chen, P. Yan, and C. Zhou, "Microseism induced by transient release of in situ stress during deep rock mass excavation by blasting," Rock Mechanics and Rock Engineering, vol. 46, no. 4, pp. 859-875, 2013.

[27] K.-I. Song, T.-M. Oh, and G.-C. Cho, "Precutting of tunnel perimeter for reducing blasting-induced vibration and damaged zone-numerical analysis," KSCE Journal of Civil Engineering, vol. 18, no. 4, pp. 1165-1175, 2014.

[28] Y. G. Hu, W. Lu, M. Chen, P. Yan, and J. Yang, "Comparison of blast-induced damage between presplit and smooth blasting of high rock slope," Rock Mechanics and Rock Engineering, vol. 47, no. 4, pp. 1307-1320, 2014.

[29] H. Yu, Y. Yuan, G. Yu, and X. Liu, "Evaluation of influence of vibrations generated by blasting construction on an existing tunnel in soft soils," Tunnelling and Underground Space Technology, vol. 43, pp. 59-66, 2014.

[30] W. Lu, J. Yang, M. Chen, and C. Zhou, "An equivalent method for blasting vibration simulation," Simulation Modelling Practice and Theory, vol. 19, no. 9, pp. 2050-2062, 2011.

[31] W. A. Hustrulid, Blasting Principles for Open Pit Mining, A.A. Balkema Publishers, Brookfield, Wis, USA, 1999.

[32] A. H. XaHyKaeB, Physical Process of Rock Blasting in Mining, Mineral Press, Leningrad, Russia, 1974.

[33] J. Mazars, "A description of micro- and macroscale damage of concrete structures," Engineering Fracture Mechanics, vol. 25, no. 5-6, pp. 729-737, 1986.

[34] J. Henrych, The Dynamics of Explosion and Its Use, Elsevier Scientific Publishing Company, New York, NY, USA, 1979.

[35] J. B. Martino and N. A. Chandler, "Excavation-induced damage studies at the underground research laboratory," International Journal of Rock Mechanics and Mining Sciences, vol. 41, no. 8, pp. 1413-1426, 2004.

[36] X. Xue, W. Zhang, and X. Yang, "A damage mechanics model for porous media," Geotechnical and Geological Engineering, vol. 31, no. 2, pp. 817-825, 2013.

[37] W. Zhang and Y. Cai, Continuum Damage Mechanics and Numerical Applications, Zhejiang University Press, Hangzhou, China, 2011. 

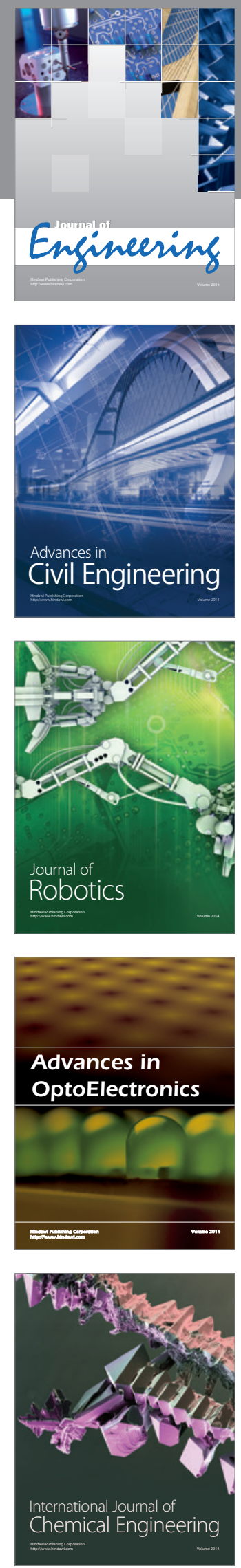

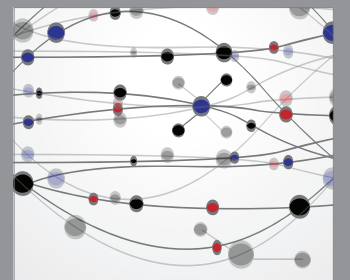

The Scientific World Journal
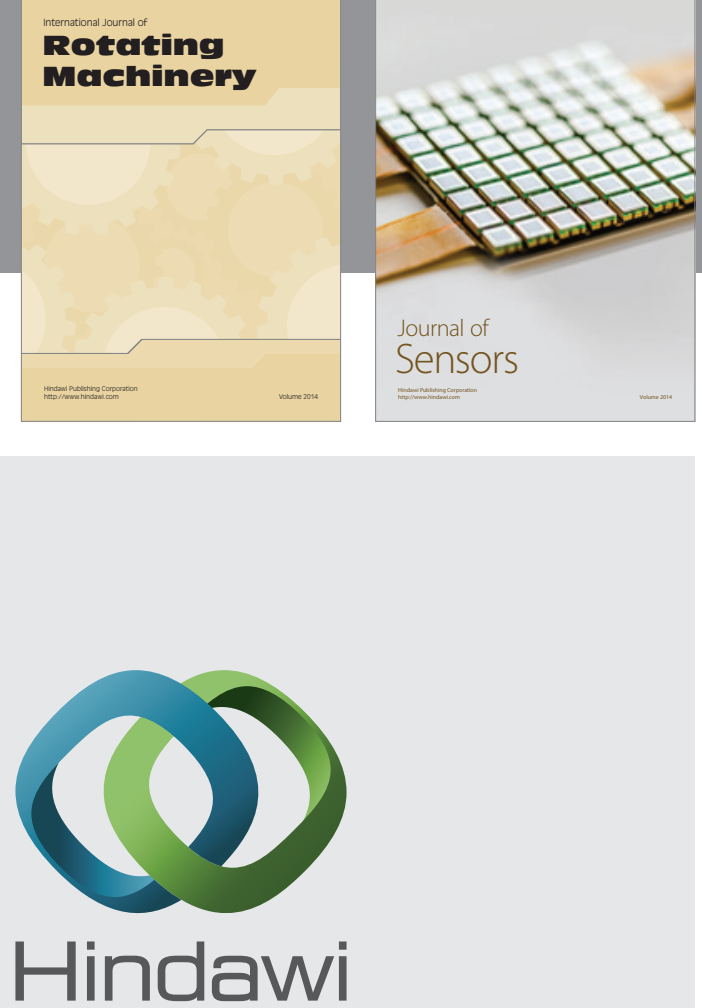

Submit your manuscripts at http://www.hindawi.com
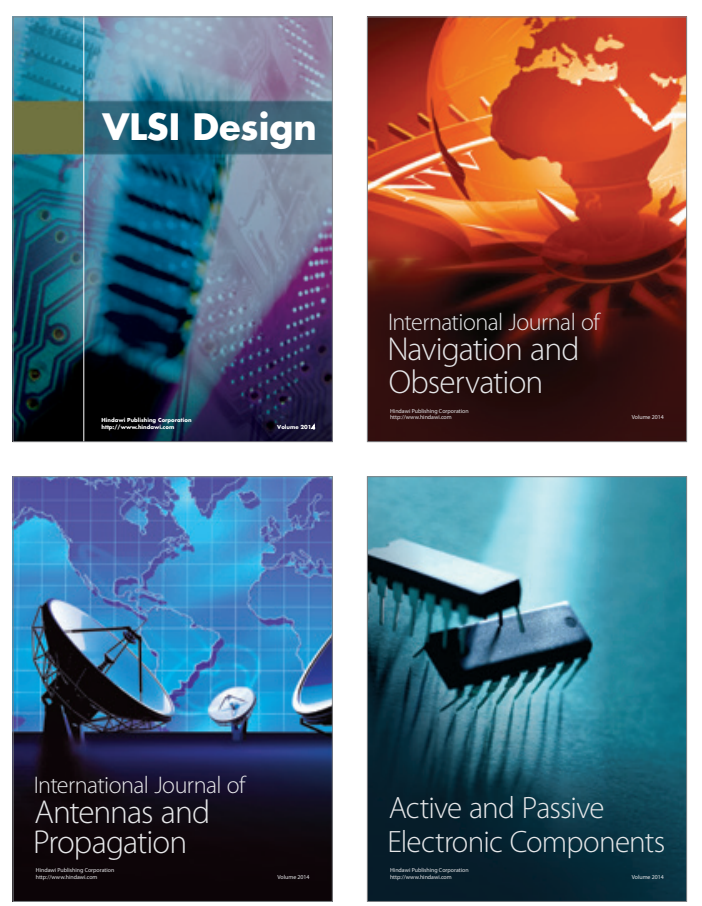
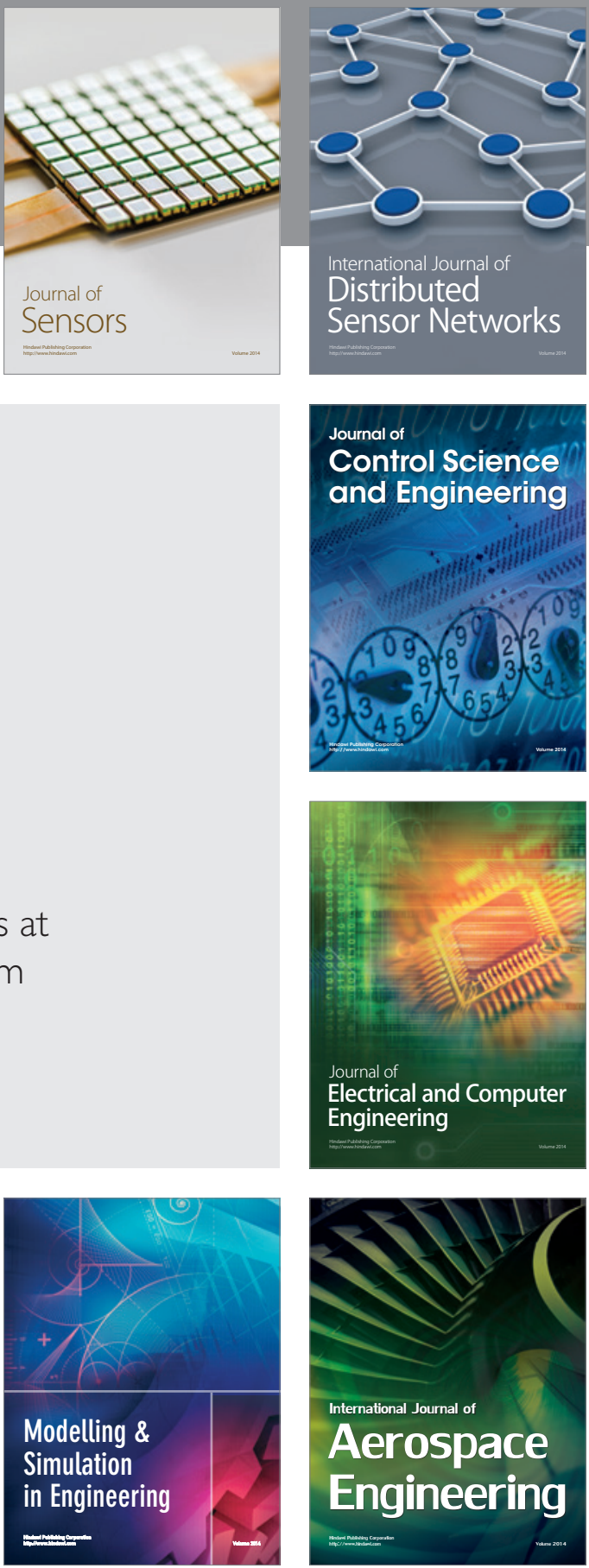

Journal of

Control Science

and Engineering
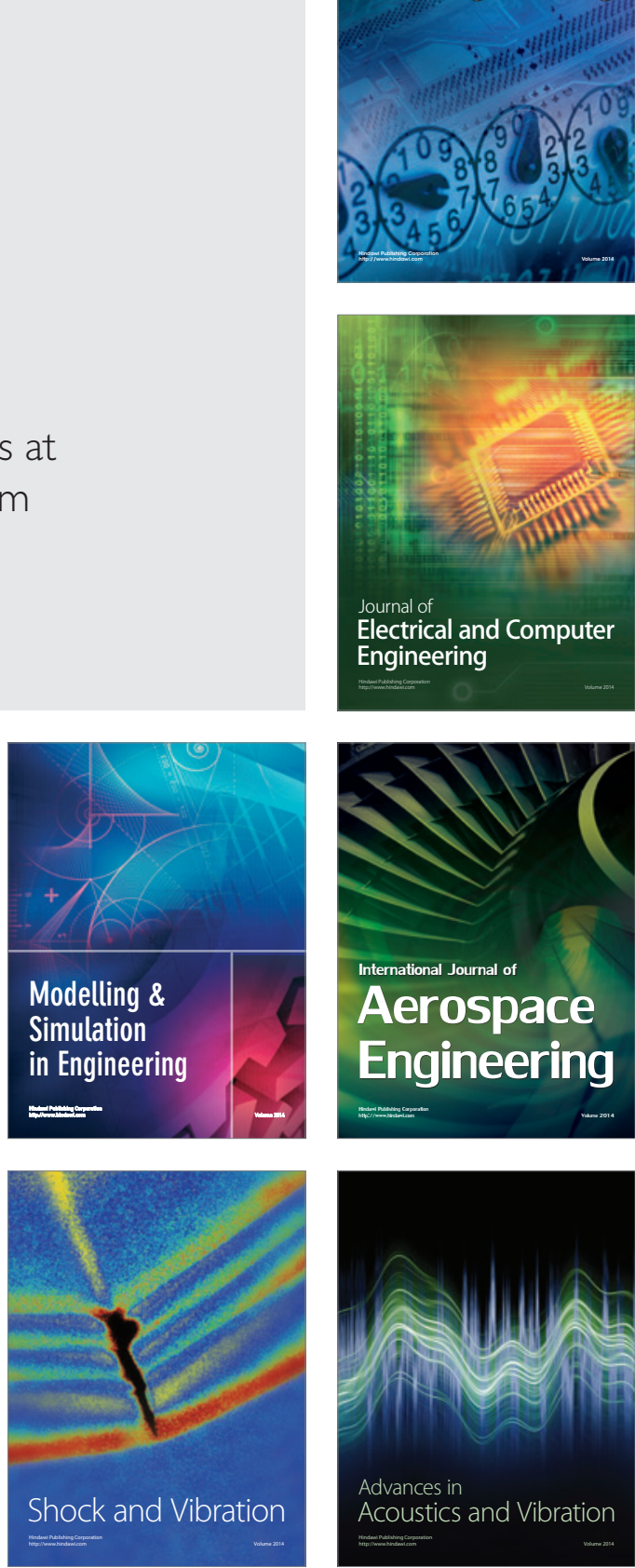